\title{
MÁS ALLÁ DEL TURISMO. REESTRUCTURACIÓN PRODUCTIVA Y CIENCIAS SOCIALES
}

Guadalupe Margarita González Hernández

Unidad Académica en Estudios del Desarrollo, UAZ

El sector turístico, inmerso en la economía mundial, está en crisis. La explicación de este problemática va más allá de la inseguridad. El estancamiento deviene de la reestructuración productiva que promueva la reducción del empleo y del tiempo de ocio, al igual que la reposición del factor trabajo. No obstante, las ciencias sociales se han dejado llevar por el espejismo, dando un motivo para la reflexión.

$\mathrm{E}$ 1 turismo es una actividad económica que en México ha sido muy poco analizada, pese a que desde 1993 representa la tercera fuente de ingresos en la balanza comercial. Para 2003, México se ubicó en el octavo lugar mundial como destino de turistas al registrar 18.7 millones de llegadas de un total de 694 millones, y en el lugar décimo tercero en cuanto a ingresos recabados, con 103.3 mil millones de pesos, $1.76 \%$ del total mundial. Para 2009, el país se situó en el décimo lugar de llegadas, con 21.5 millones de un total de 880 millones de turistas a nivel mundial, y descendió dramáticamente al lugar veinte en la percepción de ingresos, con 124.3 mil millones de pesos, es decir, el $1.3 \%$ del total mundial. ${ }^{1}$

Al igual que el resto de la economía mexicana, el turismo está en crisis no sólo por la pérdida de competitividad frente a otros destinos sino por su carácter capitalista. El discurso optimista del gobierno federal y de organismos supranacionales, como la Organización Mundial del Turismo, no tiene cabida en una actividad económica que se queja del constante declive ${ }^{2}$ en el arribo de turistas extranjeros desde 2008 y de la competencia de otros destinos mundiales con una oferta similar, y más aún de otros destinos con ofertas diferentes, como Malasia o Turquía. ${ }^{3}$

Aunque tiene su origen en historias "rosas" de magnates ricos y aventureros de países industrializados como Inglaterra y Francia, ${ }^{4}$ la industria turística alcanza su clímax en la época del Estados de bienestar. Ante las dificultades que afrontaba la acumulación capitalista, el pacto social encabezado por el Estado y el capital reconoce las virtudes de la reproducción de la fuerza de trabajo para el sostenimiento de la sociedad capitalista. Las prestaciones sociales, que contemplan jornadas laborales de 40 horas, seguridad social y derecho a vacaciones, crean las bases para que el turismo se consolide. Miles de trabajadores de países desarrollados adquieren un estilo de vida que les permite reproducirse socialmente y reponer fuerzas mediante actividades que van más allá de su descanso diario: viajar, conocer otras culturas y explorar mundos salvajes se convierten en una actividad que rentabilizan el ocio de la clase trabajadora.

Destinos como París, Nueva York, Londres, Atenas y Roma acapararon millones de turistas ávidos de conocer lo que ofrece el mercado: bienes, estética, imaginarios, herencias, estilos de vida, tradiciones. Como cualquier actividad capitalista, el turismo abrió nuevos mercados que provocaron la disputa por atraer una fuerza de trabajo viajera más sofisticada y exigente. La competencia se incrementa con la entrada de países asiáticos y latinoamericanos como nuevos destinos, aunque restringidos por su situación de subdesarrollo, para trabajadores dispuestos a viajar con ingresos y prestaciones sociales más precarios.

Con la crisis económica de la década de los setenta, el turismo mostró indicios de saturación o estancamiento. La reestructuración de la economía mundial, basada en nuevas tecnologías y orientada a mantener a flote la tasa de ganancia, provocó la flexibilización del proceso productivo y afectó la contratación de fuerza de trabajo en dos formas: 1) el incremento de la intensidad productiva, la disminución de los salarios, la prolongación de las jornadas laborales y el deterioro de las prestaciones, debilitaron los ahorros que los trabajadores reservaban para viajar; incluso el salario resultó insuficiente para cubrir las necesidades básicas. El tiempo de ocio se redujo con el aumento de las jornadas laborales mediante horas extras en busca de un ingreso adicional y la cancelación o reducción del tiempo de reposición anual como derecho; y 2) el despido masivo de trabajadores industriales y el consecuente incremento del desempleo, subempleo y autoempleo en sectores menos rentables y productivos, como los servicios, que albergaron una inmensa precarización laboral, con jornadas interminables de trabajo, ingresos magros y nulas posibilidades de prestaciones sociales, que limitaron la reposición y reproducción de los trabajadores como clase social y seres humanos. 
No es sorprendente que el turismo, a estas alturas, esté en crisis. No hay quien viaje, por lo menos de forma masiva, como tiempo atrás. Como cualquier actividad capitalista, busca nuevos mercados a través de la especialización y distinción. Destinos que antes eran clasificados como de playa, naturaleza y ciudad, se apalancan en la mercadotecnia y la creación de imaginarios para alcanzar la distinción e incrementar la capacidad de venta ante un reducido mercado de elitistas viajeros que buscan turismo "creativo", 5 "cultural", 6 "ecoturismo", 7 "tanaturismo", 8 "de aventura", " "nocturno", ${ }^{10}$ "de compras", 11 "de consumo suntuario"12 o "de entretenimiento o deportivo". ${ }^{13}$

Dada la estrategia de precarización laboral, en México es sintomático el hecho de que el empleo mal pagado y no remunerado sustenten al sector turístico. Cerca del $40 \%$ de los empleos en este sector no recibe remuneración y los trabajadores que recibe un pago perciben ingresos inferiores a dos salarios mínimos, ${ }^{14}$ un nivel insuficiente para cubrir satisfactoriamente las necesidades sociales y biológicas básicas, del propio trabajador y de su familia.

La inseguridad provocada por la lucha contra el narcotráfico - aunque considerada como un factor de "contexto", ${ }^{15}$ forma parte de la estrategia de desarrollo capitalista - ha contribuido a que el turismo se sumerja aún más en su crisis sistémica y estructural.

Ante el desarrollo rapaz del capitalismo en su fase neoliberal, el futuro del turismo es poco promisorio. Como actividad económica dependiente de un sector masivo de altos ingresos y disposición de tiempo de ocio, tiene los días contados, pues prevalece el despojo y marginación entre la mayoría de trabajadores. Tendencialmente, el turismo se reducirá, concentrará y centralizará en el mercado formado por la misma clase capitalista que lo originó.

En el ámbito de las ciencias sociales, es preocupante la insuficiencia de análisis serios y profundos, ya no digamos críticos, de la situación en México. Los planeadores y políticos suelen considerar a los estudios técnicos, desprovistos de crítica. En cambio, los estudios críticos develan el funcionamiento del capitalismo. La mayor parte de los estudios se han enfocado a impulsar, revitalizar e incrementar la competitividad de los destinos nacionales para atraer más turistas. ${ }^{16}$ Se preocupan por la crisis del turismo detonada por factores como la influenza AH1N1, 9/11, 11M y SARS, y miden flujos de turistas, entrada de divisas y niveles de consumo, pero muy pocos ven ${ }^{17}$ que, en realidad, el turismo presenta síntomas de una crisis estructural y sistémica acorde a la lógica del capitalismo contemporáneo.

La mayoría de los estudios sobre turismo refleja el componente ideológico de la corriente dominante, neoliberal, que tiene la mayor presencia en publicaciones especializadas de los países desarrollados y la mayor influencia académica en disciplinas como geografía, economía, sociología y antropología. Esto no impida que posiciones teóricas e ideológicas alternativas puedan desarrollarse. Al respecto, Latinoamérica tiene mucho que decir, ${ }^{18}$ en especial México. ${ }^{19}$ Las ciencias sociales, sobre todo la ciencia económica, están en deuda con el turismo, pues no sólo falta reconocer el ciclo de vida, importancia y e impacto para la creación, mercantilización y protección del patrimonio cultural tangible e intangible, medio ambiente e imaginarios, sino evidenciar el grado de explotación laboral, que es el principal factor que sustenta la productividad y reproducción del turismo.

\section{Referencias}

${ }^{1}$ Secretaría de Turismo (Sectur) (2009), Compendio estadístico del turismo en México, México.

2 "Demandan renovar oferta turística", El Universal, 12 de agosto de 2011, Sección Cartera, México.

${ }^{3}$ Göymen, Korel (2000), "Tourism and governance in Turkey" Annals of Tourism Research, vol. 27, no. 4, Elsevier Science Ltd., Gran Bretaña: 1025-1048.

${ }^{4}$ Williams, Paul y Geoffrey Soutar (2009) "Value, satisfaction and behavioral intentions in an adventure tourism context", Annals of Tourism Research, vol. 36, no. 3, Elsevier Ltd., Gran Bretaña: 413-438.

${ }^{5} \mathrm{Wu}$, Fulong (2000), "Place promotion in Shanghai", Cities, vol. 17, no. 5, Elsevier Science Ltd., Gran Bretaña: 349-361.

${ }^{6}$ Bryan, Jane, Steve Hill, Max Munday y Annette Roberts (2000), "Assessing the role of the arts and cultural industries in a local economy", Environment and Planning A, vol. 32, no. 8, Pion Ltd., Gran Bretaña: 1392-1408.

${ }^{7}$ Ospina, Guillermo (2006) "War and ecotourism in the national park of Colombia: some reflections on the public risk and adventure" International Journal of Tourism Research 8, John Wiley and Sons Ltd. Gran Bretaña: 241-246.

${ }^{8}$ Austin, Nathan (2002), "Managing heritage attractions: marketing challenges at sensitive historical sites", International Journal of Tourism Research 4, John Wiley and Sons, Ltd., Gran Bretaña: 447-457.

${ }^{9}$ Williams, Paul y Geoffrey Soutar (2009).

${ }^{10}$ Weindefeld, Adi, Richard Butler y Alan Williams (2010), "Clustering and compatibility between tourism attractions", International Journal of Tourism Research 12, John Wiley and Sons Ltd., Gran Bretaña: 1-16.

${ }^{11}$ Craig, David y Doug Porter (2006), Development Beyond Neo-liberalism: Governance, Poverty Reduction and Political Economy, London, Routledge.

${ }^{12}$ Park, Kwang-Soo, Yvette Reisinger y Eun-Hee Noh (2010), "Luxury shopping in tourism", International Journal of Tourism Research 12, John Wiley and Sons, Ltd. Gran Bretaña: 164-178. 
${ }^{13}$ McCarthy, John (2002) "Entertainment-led regeneration: the case of Detroit”, Cities, vol. 19, no. 2, Elsevier Science Ltd., Gran Bretaña: 105-111.

${ }^{14}$ INEGI (Instituto Nacional de Estadística, Geografía e Informática) (1989, 1994, 1999, 2004 y 2009), Censos Económicos, México.

${ }^{15}$ Baker, Michael y Stephen Page (2002), "Visitor safety in urban tourism environments: the case of Auckland, New Zealand", Cities vol. 19, no. 1, Elsevier Science Ltd., Gran Bretaña: 273-282. Fyall, Alan, Bruce Prideaux y Dallen Timothy (2006), "War and tourism: an introduction", International Journal of Tourism Research 8, John Wiley and Sons Ltd., Gran Bretaña: 153-155; Ospina, Guillermo (2006).

${ }^{16}$ Kavaratzis, Mihalis y G. J. Ashworth (2007), "Partners in coffeeshops, canals and commerce: marketing the city of Amsterdam", Cities, vol. 24, no. 1, Elsevier Ltd., Gran Bretaña: 16-25. Papatheodorou, Andreas, Jaume Rosselló y Honggen Xiao (2010), "Global economic crisis and tourism: consequences and perspectives”, Journal of Travel Research vol. 49, no. 1, Sage Publications, Estados Unidos: 39-45.

${ }^{17}$ Oktem, Kerem (2005), "Faces of the city: poetic, mediagenic and traumatic images of a multicultural city un Southeast Turkey”, Cities, vol. 22, no. 3, Elsevier Ltd., Gran Bretaña (241-253). Amin, Ash (2008), "Colective culture and urban public space”, City, vol. 12, no. 1, abril, Publisher Routledge, Gran Bretaña, pp. 5-24.

${ }^{18}$ Gorelik, Adrian (2002), "Imaginarios urbanos e imaginación urbana. Para un recorrido por los lugares comunes de los estudios culturales urbanos", Eure, vol. 28, no. 83, mayo, Universidad Católica de Chile. Duarte, Fábio (2006) "Rastros de um río urbano-cidade comunicada, cidade percibida”, Ambiente \& Sociedade, vol. IX, julio-diciembre, Núcleo de Estudos e Pesquisas Ambientais: 105-122; Andrade, Mariano (2009), "Poder, patrimonio y democracia", Andamios, vol. 6, no. 12, diciembre, Universidad Autónoma de la ciudad de México, México: 11-40.

${ }^{19}$ Hiernaux, Daniel (2005), "Imaginarios y lugares en la reconquista de los centros históricos”, Ciudades 65, enero-marzo, Benemérita Universidad Autónoma de Puebla, México: 15-21; Hernández, José (2009), “Tequila: Centro mágico, pueblo tradicional ¿¿Patrimonialización o privatización?”, Andamios, vol. 6, no. 12, diciembre, Universidad Autónoma de la ciudad de México, México: 41-67; González, Guadalupe (2012), "Imagen, satisfacción y viabilidad de proyecto turístico. Centro Histórico de Zacatecas, México”, Rodolfo García y Javier Contreras (coords.) Seminario Estatal de Universitarios: por una nueva estrategia de desarrollo integral para Zacatecas, Universidad Autónoma de Zacatecas, México: 45-69.
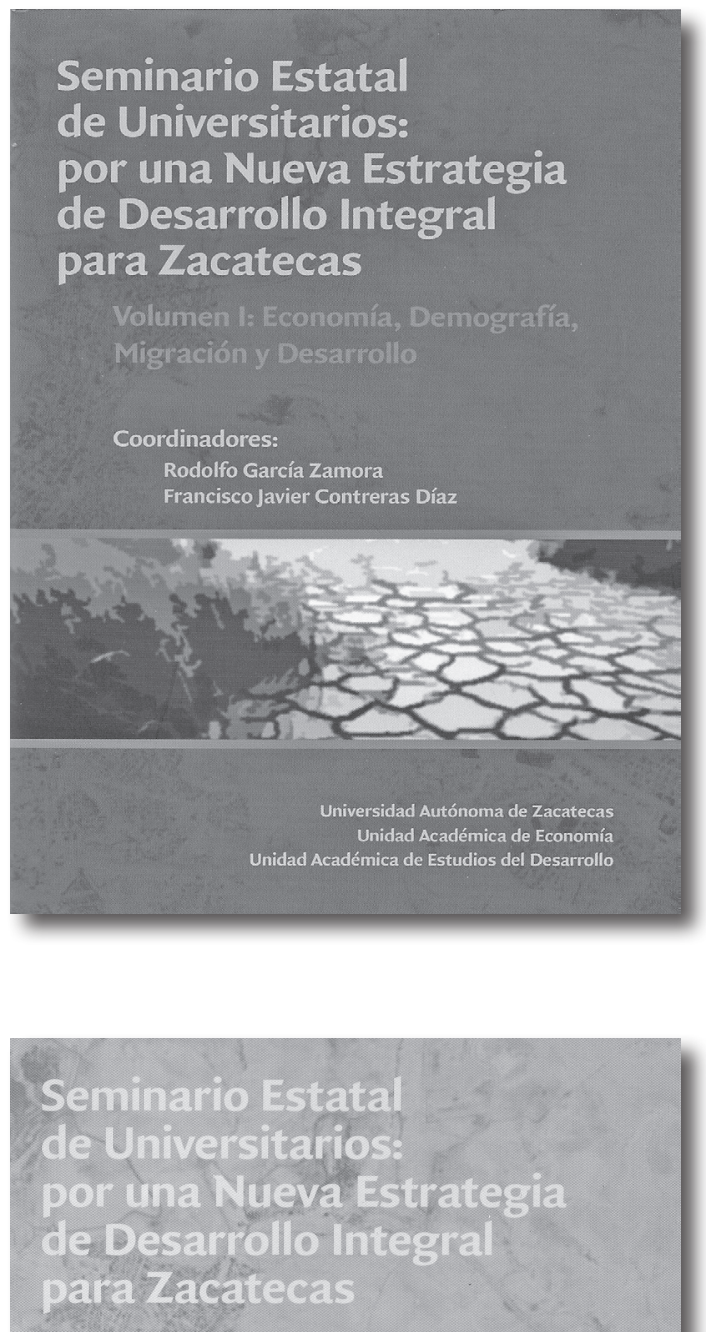

Volumen II: Políticas Públicas Sectoriales, Educación, Salud, Ciencia, Democracia y Rendimiento de Cuentas

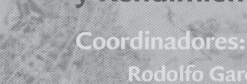
Rodolfo Carcía Zamora 3. . $_{\text {a }}$ Francisco Javier Contreras Díaz

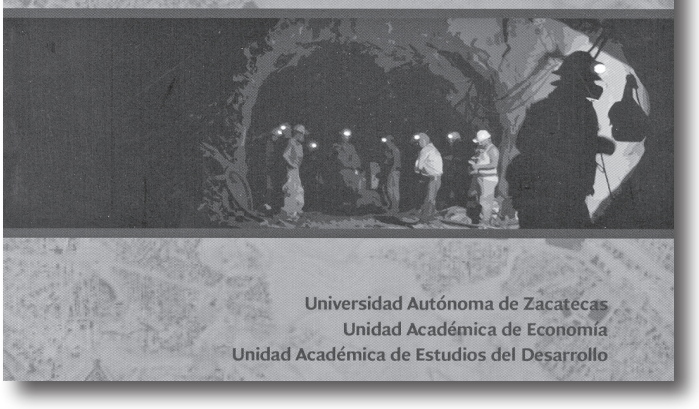

